\title{
Encontros com Jorge de Sena
}

\section{Meetings with Jorge de Sena}

EUGÉNIO LISBOA ${ }^{1}$

Resumo: Em 1972,Jorge de Sena foi a Moçama bique a convite da Associação dos Antigos Estudantes de Coimbra, tendo proferido, em Lourenço Marques, três conferências. Além disso, deu entrevistas e conversou largamente com várias figuras do meio intelectual da cidade, tendo, em tudo isso, dado evidência das suas qualidades de conversador exímio e cheio de espontaneidade e «charme». A sua prodigiosa erudição e as suas qualidades de investigador e de penetrante crítico e ensaísta foram abundantemente evidenciadas nas três lições que proferiu e nas entrevistas que deu. Durante esta sua estadia em Moçambique, Jorge de Sena aproveitou a oportunidade para visitar a ilha de Moçambique, onde Camões estacionara, no seu regresso da Índia a Portugal.

Palavras-Chaves: Encontros com Jorge de Sena; Moçambique; conferências e entrevistas de Jorge de Sena; Lourenço Marques.

\begin{abstract}
In 1972, Jorge de Sena travelled to Mozambique at the invitation of the Associação dos Antigos Estudantes de Coimbra, having given three lectures: one for the said Association, one for the University of Lourenço Marques and one at the Teatro Gil Vicente. In addition to that he was interviewed for the local radio and had conversations with many local intellectual personalities, having clearly shown his qualities as a brilliant talker full of «charme». His prodigious learning and his power as a critic and essayist were abundantly established at the occasion of the three lectures and the interviews he gave.
\end{abstract}

Keywords: Encounters with Jorge de Sena; Mozambique; Jorge de Sena's lectures and interviews; Lourenço Marques.

\footnotetext{
${ }^{1}$ Universidade de Aveiro. Nascido em Lourenço Marques (Moçambique), foi docente de literatura nas universidades dessa cidade, de Pretoria (UNISA), Estocolmo e Aveiro. Conselheiro Cultural na Embaixada em Londres (1978-1995). Presidente da Comissão Nacional da UNESCO (1995-1998). Tem vasta obra ensaística e crítica, obra poética, obra memorialista (6 vols.) e diarística (2 vols.).
} 
O meu primeiro encontro pessoal com Jorge de Sena ocorreu em Lourenço Marques (hoje, Maputo), em julho de 1972, por ocasião de uma visita sua a Moçambique, acompanhado de sua mulher, Mécia, a convite da Associação dos Antigos Estudantes de Coimbra, sediada naquela cidade. Mas conhecia a obra do escritor e a sua figura havia muito tempo. Como estudante de Engenharia, em Lisboa, entre 1947 e 1955, eu lera alguma da poesia de Sena, alguns dos seus artigos publicados na imprensa portuguesa e traduções de poemas ingleses publicados na página cultural de $O$ Comércio do Porto. E entrevira a sua figura no Café Palladium, uma noite, após um concerto ou uma ópera, acompanhado de sua mulher e de José Blanc de Portugal e respetiva mulher. Era, para mim, nessa ocasião, uma figura um bocadinho remota e um tanto intimidante. Sena tinha uma reputação - quiçá merecida - de polemista temível e contundente, de escritor ambicioso e guloso da sua glória e ressentido se lha não reconheciam, de imediato... Confesso que a sua primeira poesia não me foi de fácil adesão: parecia-me difícil, excessivamente cerebral, exageradamente construída, pouco espontânea... Mas era, desde logo, uma personalidade vigorosa que se impunha, esmagava e intimidava. Poderosamente informada, culta, como poucas.

Quando, em 1972, foi a Moçambique, eu tinha já lido bastante mais da sua obra. E tinha acompanhado, pelo número que a revista $O$ Tempo $e$ o Modo lhe dedicara, a sua fulgurante visita a
Portugal, vindo dos Estados Unidos, em 1968. Em Lourenço Marques, de resto, Sena e a sua obra eram frequente motivo de conversa, na tertúlia de que fazíamos parte eu, o Rui Knopfli, o Carlos Adrião Rodrigues e outros. O poeta de Fidelidade - sem falar no ficcionista e no ensaísta - era tido, por nós, na mais elevada conta. Foi, pois, com a maior expectativa que aguardámos a chegada do escritor e emérito professor à nossa cidade do Índico. Com uma grande expectativa e também com algum temor. $\mathrm{O}$ vigoroso e temido polemista tinha «aparecido», em seu pleno esplendor, na célebre e longa entrevista que dera ao já citado número de O Tempo e o Modo. Como seria Jorge de Sena em pessoa?

O autor de Andanças do demónio vinha de Santa Barbara (Califórnia), para onde se mudara em 1970, tendo deixado a Universidade do Wisconsin, onde vivera anos de algum desconforto. Dirigia agora, no seu novo posto, na Califórnia, dois departamentos, o que o não impedia de mostrar uma produtividade criativa de alto gabarito e fluente abundância. Inquietos, perguntávamo-nos: como será o homem? A resposta que se pode prever para esta pergunta nunca é óbvia. Tínhamos bem presente o aviso pérfido de Valéry: nunca confundir o homem que fez a obra com o homem que a obra faz supor. Quando se não atende a este aviso, corre-se, frequentemente, atrás de uma grande deceção. Neste caso, isto é, no encontro com Sena, a realidade não nos desiludiu, pelo contrário. Em conversa, Jorge de 
Sena exibia, com grande vigor, todas as qualidades intelectuais que the conhecíamos da escrita e mais uma energia vital e um «charme» extraordinários. E uma fluência e espontaneidade que nem sempre a escrita oferecia. Se me permitem, transcrevo aqui uma passagem de um testemunho que escrevi no volume III das minhas memórias (Acta est fabula - Memórias III - Lourenço Marques revisited: 1955-1976):

A «conversa» de Sena não era uma conversa qualquer e o seu «brilho» não era um foguetório vazio. Sena convocava, com mestria e leveza, todo um imponente aparato erudito com que enriquecia - sem a tornar pesada - a sua conversa. Raramente tenho conhecido um conversador deste gabarito. No livro Entrevistas - 1958/1978, recentemente publicado, poder-se-ão ler as várias entrevistas que deu, durante a sua estadia em Moçambique, muito em especial a que concedeu ao Rádio Clube de Moçambique, em 19 de julho. Ela dá uma ideia do que era e de que era feita a «conversa» de Jorge de Sena, embora, à «leitura», falte a enorme vitalidade da sua impressionante presença física. É que Jorge de Sena tinha uma impressionante presença: era alto, bem-parecido e tinha uma voz admirável e bem colocada. Era um grande senhor da língua portuguesa e era um grande senhor tout-court. Estas qualidades não «apareciam» todas, necessariamente, nos textos escritos, às vezes de uma agressividade e contundência quase intoleráveis. [...] De qualquer modo, foi um privilégio e um imenso prazer conhecê-lo. Era um homem extremamente generoso com o seu tempo e com a partilha do seu saber. (2013: 407)
Durante a sua estadia em Lourenço Marques - apenas interrompida por uma ida à ilha de Moçambique -, além das conferências a que assisti, tive ocasião de conversar com Jorge de Sena, com mais intimidade, em minha casa e em casa do Rui Knopfli, tendo então ficado subjugado pelo intenso «charme» da sua conversa vivaz. Sena sabia, com mestria, dividir cuidadosamente a sua atenção e o seu olhar por todos e cada um dos convivas presentes - sem excluir as crianças. A este respeito, gostaria de relatar aqui um facto significativo: quando, uma certa manhã, o escritor telefonou para nossa casa, quem, por acaso, atendeu o telefone foi a minha filha mais velha, então com 12 anos. Jorge de Sena, em vez de the pedir, logo, que chamasse o pai, esteve de conversa com ela uns largos minutos e só depois disso lhe pediu, finalmente, que chamasse 0 paizinho. A Geninha ficou a adorar o «Jorge»e, numa visita que este nos fez, não arredou pé do convívio, bebendo, com toda a atenção, as palavras do escritor.

Foram três as conferências que Jorge de Sena fez durante a sua estadia em Moçambique: na Associação dos Antigos Estudantes de Coimbra, apresentado por Rui Knopfli, no Teatro Gil Vicente (com apresentação feita por mim), no dia 25 (?) de julho de 1972, sobre «O vocabulário de Os Lusíadas» e, por fim, na Universidade de Lourenço Marques, sobre a «Situação actual dos estudos camonianos» com apresentação de Maria de Lourdes Cortez. 
A conferência no Teatro Gil Vicente, feita já próximo do fim da sua estadia em Moçambique, teve o seu momento de turbulência. Fiz a minha apresentação do escritor com todo o empenho (o texto foi depois publicado no Notícias da Beira, de 29 de outubro, e subsequentemente recolhida no meu livro Crónica dos anos da peste - I, 1996) e arredondei a conclusão com as seguintes palavras: «Creio que ninguém vai ter vontade de me desmentir quando eu disser que esta sua passagem por terras de Moçambique ficará como um marco inesquecível na história cultural desta terra. Cujos frutos melhores, permito-me supor, estão ainda por surgir». Sena agradeceu efusivamente as minhas palavras, mas percebia-se que ele estava estranhamente inquieto e perturbado. A razão era esta: na manhã do dia da conferência, o escritor recebera uma notícia de Lisboa acerca de uma recensão crítica desfavorável que um diário da capital publicara, relativa a um dos seus livros de traduções de poesia. À hora da conferência no Gil Vicente, o poeta de Exorcismos ainda fervia de indignação contra o perpetrador do atentado crítico. Quando, terminada a minha apresentação, lhe dei a palavra, agradeceu calorosamente, como disse, as minhas palavras introdutórias e entrou, não «em tema», mas antes em prévio «ajuste de contas» com o escriba lisboeta: esteve longuíssimos minutos a despejar o seu acumulado vinagre, o que terá deixado a sua audiência algo perplexa: nada daquilo tinha obviamente que ver com o vocabulário de Os
Lusíadas. Por fim, aliviado do lastro largado, lá entrou no assunto da conferência e deu uma lição notável, como era seu hábito.

A conferência feita na Universidade, no dia 30 (?) de julho, com o auditório cheio a deitar por fora, teve os seus antecedentes picantes. Sena era, obviamente, persona non grata para o regime vigente, mas a Universidade lá foi capaz de considerar que seria uma vergonha não convidar para discursar uma personalidade da envergadura do autor de Uma canção de Camões (a Universidade de Lourenço Marques seria, aliás, a primeira universidade portuguesa onde Sena poria os pés...). O problema, porém, era que ninguém, de entre os docentes, estava disposto a arriscar-se a apresentar em público, comprometendo-se, aquele personagem politicamente controverso e, de uma maneira geral, incómodo. Foram, portanto, passando a bola uns aos outros e acabaram por chegar ao

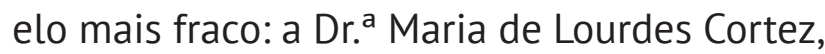
que estava nessa altura em Paris a preparar o seu doutoramento com Roland Barthes e se encontrava, de momento, em Lourenço Marques, em férias... Foi, pois, a ela que entregaram a batata quente, de que resultou, de resto, uma notabilíssima apresentação, como tal reconhecida e apreciada pelo escritor.

Durante a sua estadia em Moçambique, tive ocasião de prestar a Jorge de Sena um pequeno serviço que, na altura, me intrigou. 0 escritor veio um dia ter comigo e pediu-me, muito empenhadamente, que lhe obtivesse, se possível, 
um exemplar da $1 .^{a}$ edição de Poemas de Reinaldo Ferreira. Essa primeira edição tinha sido da responsabilidade da Imprensa Nacional, em Moçambique, e para ela tínhamos trabalhado eu próprio, o Dr. Fernando Ferreira e o Eng. ${ }^{\circ}$ Vítor Evaristo. Eu não possuía, na altura, nenhum exemplar a mais que pudesse ceder, mas lembrei-me de falar ao administrador da Imprensa Nacional, pessoa simpática e afável que, não tendo também exemplares para oferta (a edição encontrava-se totalmente esgotada), ofereceu o seu próprio exemplar, belamente encadernado. Sena agradeceu, penhoradíssimo e felicíssimo, a generosa oferta. Ora tudo isto, confesso, me intrigou, nessa altura, porquanto eu tinha conhecimento de algo que o autor de Metamorfoses tinha escrito, de muito pouco favorável à poesia de Reinaldo Ferreira. Como se compreendia, então, o seu empenho em obter a todo o custo uma primeira edição do livro de um poeta que tinha em tão pouca estima? Não fazia sentido; se em tempos não apreciara o poeta, pelo menos parecia ter mudado muito de opinião... Só muitos anos mais tarde viria eu a esclarecer este mistério, quando, um dia, num telefonema, o meu amigo Luís Amaro me contou uma história. Logo após o aparecimento do livro de Reinaldo Ferreira, em 1960, um professor brasileiro, na presença de Jorge de Sena e de Joaquim Francisco Coelho, emitiu, em conversa, a opinião de que Reinaldo Ferreira era o maior poeta português desde Fernando Pessoa. Ao ouvir isto, Sena teria entrado em fúria incontrolável, declarando perentoriamente que toda a gente deveria saber que o maior poeta português, desde Fernando Pessoa, era ele próprio, Jorge de Sena, e mais ninguém. Deve ter-se originado, neste incidente, o seu artigo em que demitia a qualidade de poeta de Reinaldo (relegando-o para a categoria de epígono de já me não recordo quem...). Mas se Sena era colérico, não era mesquinho e era, sobretudo, um excelente crítico, incapaz de não reparar na qualidade excelsa da poesia de Reinaldo. De modo que, tempos passados, já era muito capaz de lutar por uma primeira edição dos Poemas de um poeta que passara a admirar.

Tive, depois desta sua visita a Moçambique, apenas dois encontros com Jorge de Sena. Não muito depois desta viagem, eu e minha mulher almoçámos com ele, em Londres, num restaurante em Leicester Square, onde falámos descontraidamente e comemos, com apetite, um magnífico cozido irlandês. Não muito depois, estivemos com ele, em Paris, uma noite, em casa de José Terra. Guardo destes dois encontros uma boa recordação do conversador exímio e afável que era Jorge de Sena. De Santa Barbara, ainda me acenou, para Moçambique, um convite para eu ir, como leitor, para Cardiff (País de Gales), com a promessa implícita de vir a ser dali chamado, ulteriormente, para Santa Barbara, onde ficaria a trabalhar com o próprio Sena. O convite era aliciante e altamente lisonjeiro por vir de quem vinha, mas eu não estava, nessa altura, preparado para abandonar Moçambique e a minha profissão 
por um lugar de leitor. Era talvez um erro da minha parte, mas hoje, tudo visto a distância e tendo em conta o rumo que viria a tomar a minha vida, não me arrependo da minha decisão, muito embora tenha, sem dúvida, perdido uma grande oportunidade de beneficiar do convívio enriquecedor desse escritor e professor excecional que foi Jorge de Sena.

\section{Bibliografia}

Lisboa, E. (1996). Crónica dos anos da peste. Opera Omnia. Guimarães;

Lisboa, E. (2013). Acta est fabula - Memórias III Lourenço Marques revisited: 1955-1976. Opera Omnia. Guimarães. 